\title{
衛星夜間光観測データを用いた銅のストック解析
}

\author{
高橋和 枝 $1,2, *$ \\ 寺角隆太郎1,* \\ 中村二朗 2 \\ 醍 醐 市 朗 1 \\ 松 野泰 也 ${ }^{1}$ \\ 足立芳寛 ${ }^{1}$
}

\author{
1東京大学大学院工学系研究科 \\ ${ }^{2}$ 日本電信電話株式会社 NTT 環境エネルギー研究所 \\ J. Japan Inst. Metals, Vol. 72, No. 11 (2008), pp. 852-855 \\ (C) 2008 The Japan Institute of Metals
}

\section{Analysis of In-Use Stock of Copper by Using Satellite Nighttime Light Observation Data}

Kazue Ichino Takahashi1,2,*, Ryutaro Terakado ${ }^{1, *}$, Jiro Nakamura ${ }^{2}$, Ichiro Daigo ${ }^{1}$, Yasunari Matsuno ${ }^{1}$ and Yoshihiro Adachi ${ }^{1}$

${ }^{1}$ Department of Materials Engineering, Graduate School of Engineering, The University of Tokyo, Tokyo 113-8656

${ }^{2}$ NTT Energy and Environment Systems Laboratories, Nippon Telegraph and Telephone Corporation, Atsugi 243-0198

We developed a novel methodology to analyze world-scale stock-in-use of copper by using a nighttime light image. Radiance calibrated nighttime light imaged data $(\mathrm{RCD})$ of the world has been assembled from the Defense Meteorological Satellite Program (DMSP) Operational Linescan System (OLS) by the National Geophysical Data Center. It has been recognized that the intensities of nighttime light are strongly associated with human settlement, such as population density and energy consumption. We assumed that wherever the light exists the electrical conducting material, such as copper should be used. The stock-in-use data of copper such as in Japan, North America, Australia and China were obtained from existing studies on material flow analysis. We analyzed the relationship between the light accumulation density and the amount of stock of copper in those countries. A significant correlation was found and the feasibility of this method was confirmed. We applied this method to analyze stock-inuse in other Asian countries. The in-use stock of copper was correlated with gross domestic product (GDP).

(Received March 27, 2008; Accepted July 25, 2008)

Keywords: resource recycling, copper stock, defense meteorological satellite program/operational linescan system, satellite, remote sensing, nighttime light image

\section{1.は じめに}

資源循環を促進する上で，マテリアルフローを把握するこ とは有効な回収システムを構築する上で必要不可欠である. マテリアルフローを把握する手法として, マテリアルフロー 解析 (Material Flow Analysis, MFA) とサブスタンスフロー 解析 (Substance Flow Analysis, SFA)が知られている. $\mathrm{MFA} / \mathrm{SFA}$ 解析の既存研究として, 世界の銅 ${ }^{1-3)}$, 銀 ${ }^{4)}$, ク ロム ${ }^{5)}$, 鉄6,7) に関するマテリアルフローが報告されている. また過去のストックとフローが資源保護に重要な情報を与え うるとして, MFA/SFA 動的モデルが, 近年, 注目を集め ている．そこでさまざまなマテリアルと物質について動的マ テリアルフロー分析が報告されている。例えば鉛8), 鉄 $^{9,10)}$, ニッケル ${ }^{11)}$, 銅 $^{12,13)}$, アルミニウム ${ }^{14,15)}$, ステンレ 又鋼16)などである。これらの報告において, マテリアルサ イクルシステムはダイナミックに表現され, 廃棄物発生量と 収集量を推定することにより環境への排出量が可視化されて いる. 中でもマテリアルストックを第二の資源として注目

\footnotetext{
* 東京大学大学院生 (Graduate Student, University of Tokyo)
}

し，オランダの鉛ストック ${ }^{8)}$, 日本 ${ }^{10)} \cdot$ アメリカ17)の鉄鋼, アメリカ12) 抢よび北米18)の銅の過去のストック量を定量化 した報告もある．さらに Gordon らは，金属のストックを分 析することにより金属消費の持続可能性を議論している ${ }^{19)}$.

MFA/SFA に拝いてストックを推定する方法は，トップ ダウン手法とボトムアップ手法の二つに大別できる.ここ で, トップダウン手法とは, 各種素材の生産統計や産業連関 表などの統計データと, 素材の最終用途製品の寿命分布か ら, 社会中の素材蓄積量を試算する手法であり, 既存のマテ リアルフロー分析の多くはこの手法を用いている. それに対 して, ボトムアップ手法とは, 統計データなどが得られない 場合に, 対象とする地域において使用されている製品の数を 推計し，その製品に含有される素材成分に関するデータから 素材の蓄積量を積算する手法であり, G. Xueyi などの事例 研究がある20).

しかしながら途上国などの各種データが未整備の国々に関 しては, どちらの手法でも銅ストックを推定することは困難 である.

そこで本研究では, 米国軍事気象衛星 DMSP / OLS (Defense Meteorological Satellite Program/Operational Linescan System)より撮影された夜間の地球表面の観測光と 
人間の経済活動に密接な関係があることに注目した。夜間の 地上を衛星から撮影した写真は，近年，一般にも関心を集め ており，エネルギー消費や GDP などの経済活動と相関があ ることが報告されている21,22)。経済活動の結果である銅ス卜 ックも光強度と強い関係があると推定できる.すなわち, 人 口の光があるところには電気があり, 送電ケーブルを構成す る銅が使われているはずである。しかしながら，これまでに このような光量と銅ストック量の相関を検討した例はない. また，地球全土のデータが入手できる夜間光観測データを使 うことにより，データ未整備地域でも銅ストックを同様に推 定することが期待できる，本報では，夜間光から銅ストック を推定する手法を開発したので報告する.

\section{2. 分 析 手 法}

\section{1 銅ストックの推定方法}

夜間光観測データを対象国または地域に分割した。次にヒ ストグラム解析により光強度の分布図を作成し, 式 (1)に 定義する光蓄積量 (Illuminated Urban Area (IUA) dome volume)を評価した ${ }^{21)}$.

光蓄積量 $=\Sigma($ 輝度 $\times$ ピクセル数 $)$

解析の一例を Fig. 1 に示す.

銅ストックに関しては, 後述する既存研究 $10,18,20,23)$ から求 め，光蓄積量との関係をプロットした.

\section{2 用いたデータ}

\subsection{1 夜間観測デー夕}

夜間観測データは米国の軍事気象衛星により撮影された夜 間の光強度画像データ (Defense Meteorological Satellite Program/Operational Linescan System, DMSP/OLS)を, C. D. Elvidge ら ${ }^{22)}$ が加工した 1996 年から 1997 年(1996 年 3 月お よび 1997 年 1-2 月)の輻射低標夜間灯光強度データ (Radiance calibrated nighttime lights imaged data, RCD) 24)を用い た。 RCD は DMSP/OLSのゲインが異なる画像を重ね合わ せて作成されたものであり，センサーのゲインの変動による 影響を除去されるため，輝度が飽和することなく光蓄積量を 定量化できる利点がある．またこの光量の情報は地図にマッ
ピングされた形で提供されているため，国・地域別の解析が 可能である。一例としてこの RCD データより光蓄積量を求 め，人口や電力消費量に正の相関があることが報告されてい る22)。このように RCD データは地球全土を対象に経済活動 を推定する指標の一つとして用いられている.

\subsection{2 銅ストックの量}

オーストラリア全体及び州別の銅ストックの量は，D．van Beers らが，代表的な製品の銅の濃度に製品の量を掛け合わ せ，積算することにより求めた值23)を用いた。北アメリカ の銅ストック量は S. Spatari らによるサブスタンスフロー解 析に拈いて，寿命分析モデルに基づいて求めた銅ストック 量18)を用いた。 日本の銅ストックは醍醐らの文献10)におけ るポピュレーションバランスモデルにより求められた值を参 照した。さらに中国の銅ストックは G. Xueyi らによる銅の マテリアルフロー分析 ${ }^{20)} に あ る$ 各年の導入量々廃棄量から 著者らが推算した。 また世界全体, スイスおよびスェーデン の銅ストックは D. van Beers らの既報23)に記載されている 各国の stock/capita から，著者らが推算した值を用いた。 使用した銅ストックの量，対応年度，文献を Table 1 に示 す. 複数のデータがあるものはその平均とし，また対応年度 が明らかではない場合は文献の発行年とした。

Table 1 In-use stock of copper.

\begin{tabular}{lcll}
\hline \multicolumn{1}{c}{ Region } & Copper stock $(\mathrm{Gg})$ & Year & \multicolumn{1}{c}{ Reference } \\
\hline World & $284000^{* 1}$ & $2001^{* 2}$ & D. van Beers ${ }^{23)}$ \\
\hline North America & 70000 & 1999 & S. Spatari ${ }^{18)}$ \\
\hline USA & $77605^{* 1}$ & $1999^{* 2}$ & D. van Beers ${ }^{23)}$ \\
\hline Japan & 19000 & 2000 & I. Daigo ${ }^{10)}$ \\
\hline China & 11000 & 2000 & G. Xueyi ${ }^{20)}$ \\
\hline Australia & 4300 & 2000 & D. van Beers ${ }^{23)}$ \\
\hline Sweden & 1200 & $2003^{* 2}$ & D. van Beers ${ }^{23)}$ \\
\hline Swiss & 1600 & $2003^{* 2}$ & D. van Beers ${ }^{23)}$ \\
\hline
\end{tabular}

*1 The average is shown.

*2 The publication date is shown.
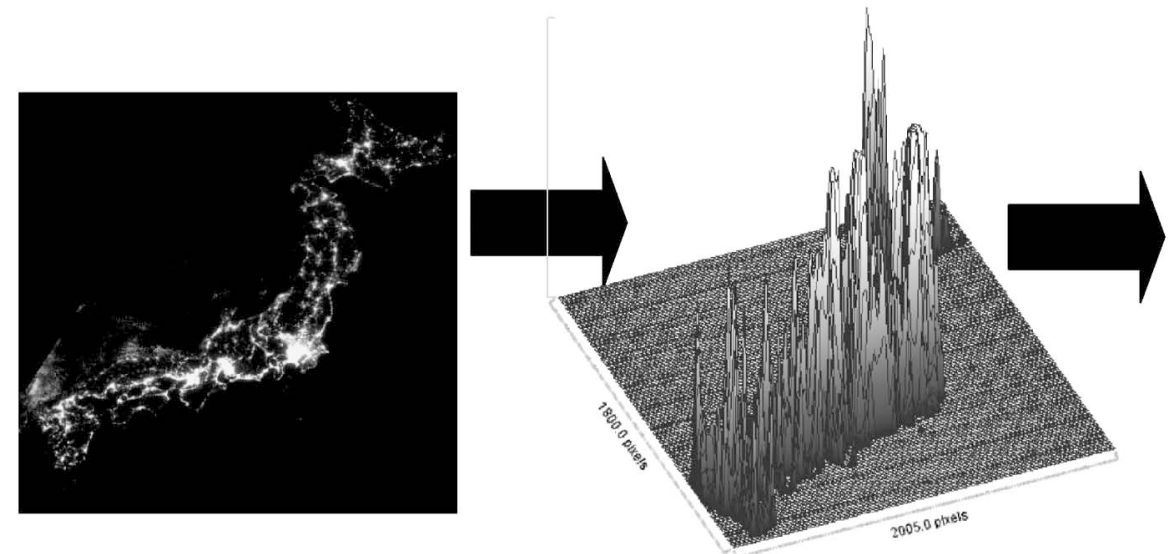

Fig. 1 The imaging analysis.

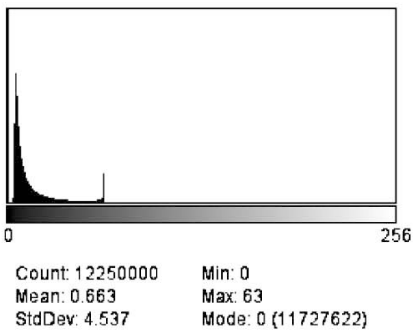




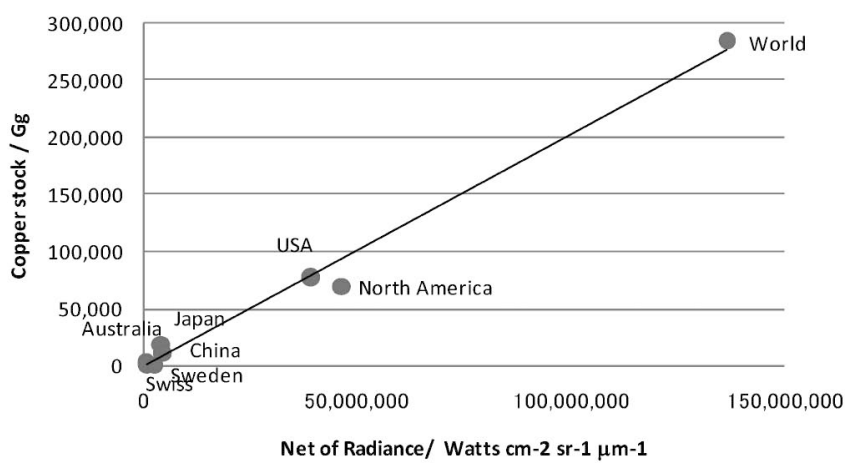

Fig. 2 The relationship between net of radiance and copper stock.

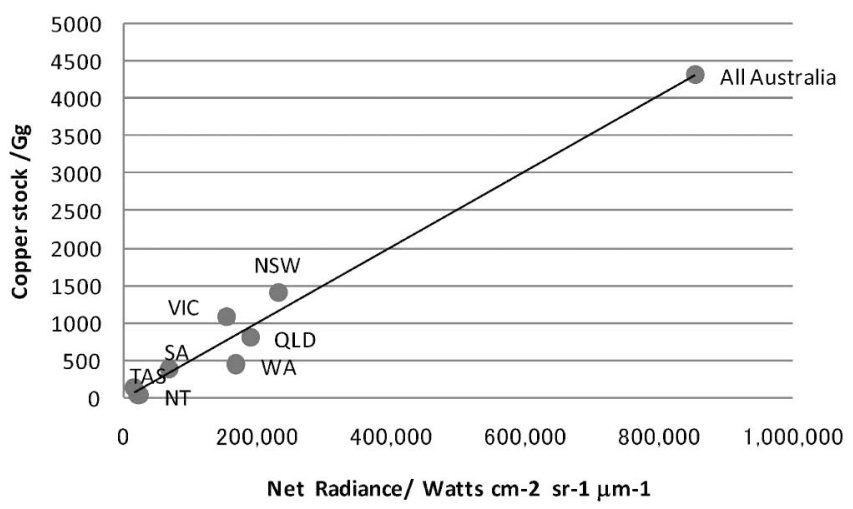

Fig. 3 The relationship between net of radiance and copper stock in Australia.

\section{3. 銅ストックと光蓄積量の関係}

\section{1 国レベルでの銅ストックと光蓄積量の関係}

日本, 北アメリカ, 中国, スイス, スェーデン, アメリカ 合衆国, オーストラリアおよび世界全体の光蓄積量と銅スト ックの関係を Fig. 2 に示す.

銅ストックと光蓄積量には強い相関 $\left(R^{2}\right.$ は 0.99$)$ があり, 光蓄積量から国レベルの銅ストックを推定できることが明ら かとなった。

\section{2 オーストラリア国内での銅ストックと光蓄積量の関係}

次に地域別のストックの推定に使用できるかどうかをオー ストラリアの各州の銅ストック量 ${ }^{23)}$ と光蓄積量の関係から 調べた。 その結果を Fig. 3 に示す. 図に示したようにより 狭い対象範囲であっても両者には強い相関 $\left(R^{2}\right.$ は 0.97$)$ があ り，適用可能であることが示唆された。

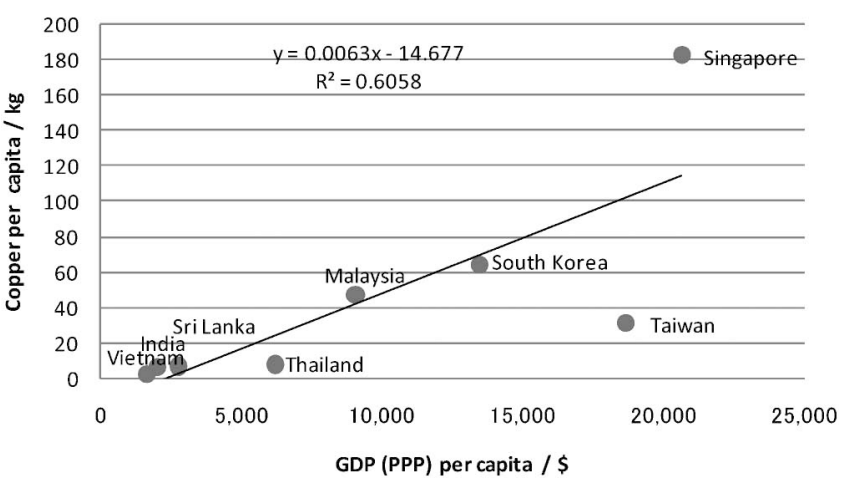

Fig. 4 Relationship between estimated copper stock/capita and GDP/capita.

\section{3 本手法のアジア各国への適応}

次に銅ストックの量が明らかではなく，データも未整備で あるアジア諸国について光蓄積量を測定し，3.1の結果から 銅ストックを推計した. 結果を Table 2 に示す.

Binder らは銅の単年 (1994 年)のフローを 50 カ国につい て解析し, 購買力平価(purchasing power parity, PPP)あた りの GDP と強い相関があることを明らかにしている25)。そ こで本研究でも銅ストックと GDP (PPP) との関係を求め た. 結果を Fig. 4 に示す. Fig. 4 より, 両者には直線の相 関関係 $\left(R^{2}\right.$ は 0.61)があることが示された. Binder らの論文 では単年でのフローを解析し, 本論文ではストックを解析し ているが，ストックに関しても GDP (PPP) との正の相関を 示す結果が得られた.

\section{4. 結 論}

衛星から観測される地表夜間光と銅ストックには強い相関 があるが明らかとなり, 新たな銅ストックのボトムアップ推 定手法が開発できた。本手法は世界, 国だけではなく州など の地域単位でも利用可能である.さらに本手法使って，銅又 トック量が不明なアジア地域に適用したところ，GDP との 強い相関があり，既存研究において銅のフローとGDP に強 い相関を示した結果と同じ傾向を示している. 今後, 推定し た銅ストックを他の手法で検証するとともに他のマテリアル についても同手法が適応可能であるかを検討していく.

独立行政法人国立環境研究所の一ノ瀬俊明様には本研究に 対し，有益なコメントをいただきました。ここに感謝いたし ます。

Table 2 Estimated In-use stock of copper in Asian countries.

\begin{tabular}{lrrrrrrrr}
\hline & \multicolumn{1}{c}{ India } & South Korea & Malaysia & Singapore & Taiwan & Thailand & Vietnam & Sri Lanka \\
\hline Net of radiance/Watts cm-2 sr-1 mm-1 & 3030000 & 1470000 & 485000 & 346000 & 339000 & 235000 & 94400 & 63500 \\
\hline Copper stock $/ \mathrm{Gg}$ & 6000 & 2900 & 970 & 690 & 680 & 470 & 190 & 130 \\
\hline
\end{tabular}




\section{文献}

1) T. E. Gradel, M. Bertram, K. Fuse, R. B. Gordon, R. Lifset, H. Rechberger and S. Spatari: Ecological Economics 42(2002) 926

2) T. E. Graedel, D. Beers, M. Bertram, K. Fuse, R. B. Gordon, A. Gritsinin, A. Kapur, R. J. Klee, R. J. Lifset, L. Memon, H. Rechberger, S. Spatari and D. Vexler: Environ. Sci. Technol. 38 (2004) 1242-1252.

3) S. Murakami, M. Yamanoi, T. Adachi, G. Mogi and J. Yamatomi: Mater. Trans. 45, (2004) 3184-3193.

4) J. Johnson, J. Jirikowic, M. Bertram, D. Beers, R.B. Gordon, K. Henderson, R. J. Klee, T. Lanzano, R. Lifset, L. Oetjen and T. E. Graedel: Environ. Sci. Technol. 39 (2005) 4655-4665.

5) J. Johnson, L. Schewel and T. E. Graedel: Environ. Sci. Technol. 40(2006) 7060-7069.

6) T. Wang, D. B. Muller and T. E. Graedel: Environ. Sci. Technol. 41(2007) 1520-1529.

7) H. Yoshimoto: Tekkoukai 35, 9 (1985) 70-78.

8) A. Elshkaki, E. Voet, M. Holderbeke and V. Timmermans: Resour. Conserv. Recycl. 42(2004) 133-154.

9) I. Daigo, D. Fujimaki, Y. Matsuno and Y. Adachi: Tetsu-toHagane 91 (2005) 171-178.

10) I. Daigo, Y. Igarashi, Y. Matsuno and Y. Adachi: ISIJ Int. 47, 7 (2007) 1065-1069.

11) K. Tsunemi and H. Wada: Tetsu-to-Hagane 92, 10 (2006) 49-
56.

12) C. Zeltner, H. P. Bader, R. Scheidegger and P. Baccini: Regional Environmental Change 1(1999) 31-46.

13) S. Spatari, M. Bertram, K. Fuse, T. E. Graedel, H. Rechberger: Ecol. Econ. 42(2002) 27-42.

14) M. T. Melo: Resour. Conserv. Recycl. 26(1999) 91-113.

15) H. Hatayama, H. Yamada, I. Daigo, Y. Matsuno and Y. Adachi: Mater. Trans. 48(2007) 2518-2524.

16) Y. Igarashi, I. Daigo, Y. Matsuno and Y. Adachi: ISIJ Int. 47 (2007) 753-757.

17) D. B. Muller, T. Wang, B. Duval and T. E. Graedel: Proceedings of the National Academy of Sciences of the United States of America 103(2006) 16111-16116.

18) M. Spatari, R. B. Bertram, K. Gordon and T. E. Henderson: Ecological Economics 54(2005) 37-51

19) R. B. Gordon, M. Bertram and T. E. Graedel: Proceedings of the National Academy of Sciences of the United States of America 103(2006) 1209-1214.

20) G. Yueyi and S. Yu: Resources, Conservation and Recycling 52(2008) 874-882.

21) R. Welch: Remote Sensing of Environment 9(1980) 1-9.

22 ) C. D. Elvidge, K. E. Baugh, J. B. Dietz, T. Bland, P. C. Sutton, and H. W. Kroehl: Remote Sens. Environ. 68 (1999) 77-88.

23) D. Beers and T. E. Graedel: Journal of Cleaner Production $15(2007) 849-861$.

24) http://www.ngdc.noaa.gov/dmsp/download_rad_cal_96-97. html

25) C. R. Binder, T. E. Graedel and B. Reck: Journal of Industrial Ecology 10(2006) 1-2, 111-132. 